\title{
Aportaciones franciscanas al republicanismo político $^{1}$
}

\section{Franciscan Contributions to Political Republicanism}

\author{
Esteban Anchústegui Igartua ${ }^{2}$ \\ Universidad del País Vasco UPV/EHU (España) \\ ORCID: https://orcid.org/0000-0001-8471-7305
}

Manuel Lázaro Pulido ${ }^{3}$

UNIR (España) - Universidad Bernardo O’Higgins (Chile)

ORCID: https://orcid.org/0000-0002-0064-5293

Recibido: 01-11-2020

Aceptado: 10-06-2021

\section{Resumen}

En el presente artículo pretendemos presentar algunas bases medievales, especialmente franciscanas, del revitalizado republicanismo cívico del siglo XX. Existe un salto injustificado de Roma al Renacimiento que tiene su origen en el

${ }^{1}$ Este trabajo ha sido elaborado en el marco del proyecto de investigación "Biografía colectiva y análisis prosopográfico más allá del Parlamento" del MICIU (PGC2018-095712-B-100) dentro del Grupo de Investigación consolidado tipo A del Gobierno Vasco Biography \& Parliament (IT-1263-19).

2 (esteban.antxustegi@ehu.eus) Profesor Titular de Filosofía Moral y Política en la Universidad del País Vasco UPV/EHU. Grupo Consolidado de Investigación tipo A del Gobierno Vasco Biography \& Parliament. Premio Lehendakari Agirre de la Diputación Foral de Gipuzkoa (España) en 2011, destinado a reconocer la investigación en el campo de la ciencia política. Señalar, entre sus libros, El debate nacionalista: Sabino Arana y sus herederos (2007, Editum, Murcia) y El tiempo de la Filosofía Politica (2013, Grijley, Lima).

${ }^{3}$ (manuel.lazaro@unir.net) Catedrático de Filosofía Jurídica en la Facultad de Derecho de la Universidad Internacional de La Rioja (UNIR) e Investigador asociado del Dep. de CC. del Derecho de la Universidad Bernardo O’Higgins, Chile. Director del GI UNED: "Hermenéutica y argumentación jurídica". Miembro de diversos grupos, institutos y centros de investigación nacionales e internacionales en las áreas de Filosofía, Filosofía jurídica y Teología. Coordinador del Seminario de Filosofía jurídica de la real Academia de Legislación y Jurisprudencia de Extremadura. Entre sus publicaciones más recientes: Historia de la filosofia medieval y renacentista I (2018, UNEDSindéresis, Madrid), (ed.) Pensar la Edad media Cristiana. Concilio, conciliarismo y teología en la Edad Media... (y otros estudios) (2020, Sindéresis-Universidad Pontificia de Salamanca, Madrid), "Constitutional Hermeneutic Principles and Constitutional Interpretation", en Encyclopedia of Contemporary Constitutionalism (2021, Springer). 
olvido y la mirada simplista que Hanna Arendt tiene del pensamiento medieval y del aristotelismo, provocado por los criterios historiográficos de su época. Para ello mostraremos algunas características del pensamiento de este nuevo republicanismo para poder presentar así algunas ideas centrales de cuatro autores franciscanos: Francesc Eiximenis, Buenaventura, Duns Escoto y Alfonso de Castro. Antes intentaremos mostrar la continuidad existente entre Edad Media y Moderna. Con esta aproximación histórica pretendemos analizar que la legítima aspiración de este nuevo republicanismo queda desvirtuada y limitada si deja de lado aportaciones medievales que ayudan a entender más cabalmente la pretensión republicana que, sin rechazar la autonomía del individuo ni el sentido de comunidad, destaca la naturaleza interactiva de la vida social e instiga a perseverar en la búsqueda del bien común.

Palabras-clave: Hannah Arendt, republicanismo cívico, filosofía medieval, pensamiento franciscano, Duns Escoto.

\begin{abstract}
In this paper we intend to present some medieval foundations, especially Franciscan, of the revitalized civic republicanism of the 20th century. There is an unjustified leap from Rome to the Renaissance that has its origin in the forgetfulness and simplistic view that Hanna Arendt has of medieval thought and Aristotelianism, caused by the historiographic criteria of her time. For this we will show some characteristics of the thought of this new republicanism in order to present the central ideas of four Franciscan authors: Francesc Eiximenis, Bonaventure, Duns Scotus and Alfonso de Castro. First we will try to show the continuity that exists between the Middle Ages and the Modern Age. With this historical approach we intend to analyze that the legitimate aspiration of this new republicanism is distorted and limited if it leaves aside medieval contributions that help to understand more fully the republican pretension the republican pretension that, without rejecting the autonomy of the individual or the sense of community, highlights the interactive nature of social life and instigates him to persevere in the pursuit of the common good.
\end{abstract}

Keywords: Hannah Arendt, Civic Republicanism, Medieval Philosophy, Franciscan Thought, Duns Scotus.

\title{
Introducción
}

El republicanismo representa la extensa y variada tradición del pensamiento político que se fundamenta en la libertad y el autogobierno. Desde la segunda 
mitad del siglo XX la teoría política asociada al republicanismo ha tenido un evidente renacimiento, tanto de la mano de historiadores de las ideas políticas que han tratado de hacer una reconstrucción historiográfica de su legado como por medio de filósofos políticos, juristas o politólogos, catalogados como neorepublicanos ${ }^{4}$, que han encontrado en su actualización una concepción de la política agrupada en torno a la noción de ciudadanía. En definitiva, a pesar de no postularse como una teoría unitaria, estable y acabada, este republicanismo se siente en condiciones de ofrecer un lenguaje y una alternativa vigorosa a los retos de las actuales sociedades pluralistas frente a las insuficiencias del liberalismo o el comunitarismo, al mismo tiempo que, a través de la participación y el desempeño del deber cívico, considera factible asegurar un sistema normativo equitativo que se establece y sustenta en instituciones políticas apreciadas y compartidas.

Partiendo de esta premisa, lo que este artículo pretende es analizar que esta pretensión republicana no puede ser comprendida debidamente si se prescinde de las aportaciones medievales que, conjugando la dignidad y autonomía de la persona con el proyecto de comunidad, destacan la condición interactiva de la vida social e impulsan a los miembros de la colectividad a promover las condiciones que propicien el bien común.

\section{La pretensión republicana}

Los neo-republicanos resaltan especialmente la libertad política, subrayando que el valor republicano más característico es la libertad, que sólo tiene sentido cuando es vivida como no-dominación y es entendida como ausencia de servidumbre (Pettit 1999, 41-42), interpretando la libertad "no como un dato de la naturaleza, sino como el estatuto de un ciudadano en un orden jurídico adecuado" (Spitz 1995, 208).

Este orden jurídico es el autogobierno republicano, fundamentado en una práctica política compartida dentro de una comunidad de ciudadanos libres, que entienden que su libertad toma sentido y está garantizada por la existencia de unas instituciones y con el compromiso generado hacia ellas, para lo que se constituyen en una "república equilibrada (polity) [...] en que la materia humana desarrollaba su propia virtud y la función de la virtud era imponer una forma a la materia de la fortuna" (Pocock 2017, 272). Estas instituciones garantizan la erradicación de cualquier tipo de ligamen que pudiera reproducir relaciones del tipo amo y esclavo o de amo y siervo, de modo que en ningún

\footnotetext{
${ }^{4}$ Entre estos autores, por citar algunos reseñados en el artículo, podríamos señalar a Hannah Arendt (1958), Hans Baron (1967), John G. A. Pocock (1975), Quentin Skinner (1998), Jean-Fabien Spitz (1995), Philip Pettit (1997) o Maurizio Viroli (1999).
}

Araucaria. Revista Iberoamericana de Filosofía, Política, Humanidades y Relaciones Internacionales, año $23, \mathrm{n}^{\circ} 48$. Tercer cuatrimestre de 2021. Pp. 9-31. ISSN 1575-6823 e-ISSN 2340-2199 https://dx.doi.org/10.12795/araucaria.2021.i48.01 
momento "la parte dominante pueda interferir de manera arbitraria en las elecciones de la parte dominada" (Pettit 1999, 41). Las instituciones son la columna vertebral del autogobierno republicano, cuya preservación y defensa solo se puede lograr a través de la participación activa en el ámbito público ${ }^{5}$, que es donde se construyen y legitiman los acuerdos y normas que rigen la forma de vida compartida.

Con todo, hay que diferenciar entre dominación e interferencia. Pettit señala que es factible la existencia de dominación sin interferencia, de igual manera que puede darse la interferencia sin dominación. Así, se puede estar dominado por otro sin que ello suponga interferencia alguna en mis elecciones, tanto por la disposición afable y no-interfiriente del dominador, como por mi propia habilidad para "salirme siempre con la mía". Pero también se puede sufrir interferencia sin ser dominado, permitiendo que una persona o una institución "se relacione conmigo en calidad, no de amo, sino más bien al modo de un agente que disfruta del poder de gestionar o procurar en mis asuntos" (Pettit 1999, 42).

Por tanto, si bien es cierto que el ideal republicano de libertad se basa en la no-dominación, en oposición a la servidumbre, de manera que el siervo se encuentra a merced de la voluntad de otro, atemorizado por su condición dependiente y degradado moralmente; la ausencia de interferencia (característica de la libertad negativa liberal) no supone, en la concepción republicana, la exención de cualquier interferencia, sino la eliminación expresa de la interferencia arbitraria (Pettit 1999, 45). En la misma línea, Skinner advierte que, con la hegemonía de la teoría liberal en la filosofía política contemporánea, se ha perdido de vista la teoría neorromana, que "pone en duda, precisamente, la suposición de que la libertad individual sea básicamente un asunto de no interferencia" (Skinner 2004, 72-73).

Esta singularidad es fundamental para entender el pensamiento republicano. De hecho, los dos elementos imprescindibles para constituir esta comunidad autogobernada son el estar en contacto con los otros y la existencia de la esfera pública de semejantes. A este respecto, la excelencia -areté para los griegos y virtus para los romanos- se ha atribuido desde siempre en la esfera pública, que es donde cabe sobresalir y distinguirse de los demás. Como señala Arendt, "toda actividad desempeñada en público puede alcanzar una excelencia nunca igualada en privado, porque esta, por definición, requiere la presencia de otros, y dicha presencia exige la formalidad del público, constituido por los pares de uno, y nunca la casual, familiar presencia de los iguales o inferiores a uno" $(2009,58)$. Incluso la particularidad de la condición de esclavo era la de quien "no era admitido en la esfera pública, donde puede mostrarse la excelencia" (Arendt 2009, 90). Este sentido de libertad política se presenta como el valor fundamental de interpretación del republicanismo clásico.

\footnotetext{
${ }^{5}$ La cosa pública, la república.
} 
Además, no podemos sustraernos al hecho de que el republicanismo comparte una historia que afecta a su propia percepción y conformación. Esto hace que podamos cuestionarnos si debemos hablar de republicanismo o de momentos estelares de esta teoría política, desde la antigüedad hasta la actualidad. Ello nos llevaría a plantearnos una cuestión sobre la genealogía y desarrollo del republicanismo a fin de poder plantear unas bases comunes desarrolladas desde la Roma republicana hasta, pongamos por caso, la formulación rousseauniana. En cierta forma, el criterio hermenéutico implementado por el neo-republicanismo ofrece una base a la tradición republicana representada con frecuencia por "escritores sueltos en la historia del pensamiento político occidental" (Lovett 2018), que conoce sus orígenes modernos en el Renacimiento italiano, principalmente en Maquiavelo, y continúa en el ámbito anglosajón con los republicanos ingleses -entre otros Milton, Harrington y Sidney- y los pensadores políticos del siglo XVIII, proyectándose en autores americanos como Jefferson, Madison y Adams. Sin olvidar el republicanismo francés representado en Rousseau, con su propia deriva totalitaria y abogando porque "el pacto social no sea un vano formulario, [lo que] implica [...] que quien se niegue a obedecer la voluntad general será obligado por todo el cuerpo: lo que no significa otra cosa que se le forzará a ser libre." (1964, I [VII], 364). Con todo, a pesar de su heterogeneidad, estos autores comparten elementos comunes y un estilo retórico en los que recurren a los argumentos de autoridad de los clásicos, significativamente Cicerón, lo que ha propiciado la denominación de republicanismo clásico o neorromano. En este sentido se expresa Viroli en el primer capítulo de su obra Repubblicanesimo, (1999), recordando sus inicios en Italia, donde la República es la "cosa publica" (res publica) que Cicerón asimiló a la "cosa del pueblo" (res populi). Es decir, el bien común, el interés general, garantizado por el gobierno de la ley. Aquella idea que se recogiera en Rousseau y que explicara en un sentido retórico, cuando afirma que llama República "a todo estado regido por las leyes", incluida la monarquía. Un republicanismo que tratará de articular la libertad individual y colectiva (Antonini 2012, 109).

Más interesante que Rousseau, el republicanismo de Montesquieu consideraba que la virtud política exigía renuncia de uno mismo, y señalaba a este respecto que "se puede definir esta virtud como el amor a las leyes y a la patria. Dicho amor requiere una preferencia continua del interés público sobre el interés de cada cual" (1995, IV [V], 28-29). Para Montesquieu la virtud republicana constituye una especie de conglomerado de todas las virtudes particulares, como el patriotismo, honestidad, austeridad, integridad etc., que se erige frente a su opuesto, la corrupción, que adopta vicios como el egoísmo, orgullo, cobardía, avaricia o la ambición, por citar algunos. En definitiva, Montesquieu propone fomentar el amor a la cosa pública, porque, al contrario 
de Rousseau, concibe que "este amor afecta especialmente a la democracias. Sólo en ellas se confía el Gobierno a cada ciudadano. Ahora bien, el Gobierno es como todo el mundo: para conservarlo hay que amarlo" (1995, IV [V], 29). En definitiva, frente a la pasión y primacía que por la igualdad manifestaba el proyecto jacobino-rousseauniano, Montesquieu señala claramente cuál es el rango de sus afectos republicanos, "el amor a la República en la democracia es amor a la democracia, y éste es amor a la igualdad" (1995, V [III], 33), de donde se deduce que la igualdad es consecuencia, pero nunca origen del orden republicano. Por ello, insiste Montesquieu, "todo depende, pues, de instaurar ese amor en la República, y precisamente la educación debe atender a inspirarlo", y finaliza con una sentencia inapelable que recurre a la responsabilidad de los progenitores: "Hay un medio seguro para que los niños puedan adquirirlo y es que sus propios padres lo posean" (1995, IV [V], 29).

Ya hemos señalado, con Arendt, que la presencia en el espacio público era fundamental en la antigüedad greco-romana, hasta el punto de que "el idioma de los romanos, quizás el pueblo más político que hemos conocido, empleaba las expresiones "vivir" y "estar entre hombres" (inter homines esse) o "morir" $\mathrm{y}$ "cesar de estar entre hombres (inter homines esse desinere) como sinónimos." $(2009,22)$.

Sin embargo, para la pensadora, frente a la "la pluralidad humana, básica condición tanto de la acción como del discurso" (Arendt 2009, 200) propio de la res publica, con el crecimiento del cristianismo se fue imponiendo "la bondad en sentido absoluto, diferenciada de lo "bueno para" o lo "excelente" de la antigüedad griega y romana" (Arendt 2009, 79); lo que produjo un "antagonismo entre el primer cristianismo y la res publica, tan admirablemente resumido en la frase de Tertuliano nec ulla magis res aliena quam publica, [...] como una consecuencia de las tempranas expectativas escatológicas" (Arendt 2009, 79).

Arendt considera que también hay otra razón para la ultramundanidad cristiana de llevar una vida lo más alejada posible de la esfera pública, como es la circunstancia de que "la única actividad que enseñó Jesús con palabras y hechos fue la bondad, e indudablemente esta acoge una tendencia a no ser vista ni oída." $(2009,79)$. A este respecto, manifestaciones evangélicas como "cuando una buena acción se hace pública y conocida, pierde su específico carácter de bondad. [...] Por lo tanto: "procura que tus limosnas no sean vistas por los hombres" (o) "que tu mano izquierda no sepa lo que hace la derecha"”, (Arendt, 2009, 79-80) son expresiones elocuentes sobre la pertinencia de no hacer ostentación ni manifestación externa de la bondad.

Arendt reflexiona sobre el significado y la naturaleza que las buenas acciones y la bondad tienen para el cristianismo. Las buenas acciones, "en tanto

\footnotetext{
6 "ninguna materia nos es más ajena que la pública".
}

Araucaria. Revista Iberoamericana de Filosofía, Política, Humanidades y Relaciones Internacionales, año $23, \mathrm{n}^{\circ} 48$. Tercer cuatrimestre de 2021. Pp. 9-31. ISSN 1575-6823 e-ISSN 2340-2199 https://dx.doi.org/10.12795/araucaria.2021.i48.01 
que han de olvidarse instantáneamente, jamás pueden convertirse en parte del mundo; vienen y van, sin dejar huella" $(2009,81)$, por lo que la bondad, que es inherente a las buenas acciones, "al igual que la sabiduría en la antigüedad, (deviene en) una cualidad en esencia no humana, superhumana" (Arendt 2009, 81). Pero, no obstante, de ahí su éxito, ya que ser amante de la bondad sí forma parte de la experiencia religiosa y es universalizable, porque "el amor a la bondad, a diferencia del amor a la sabiduría, no está limitado a la experiencia de unos pocos, de la misma manera que la soledad, a diferencia de la vida solitaria, se halla al alcance de la experiencia de cualquier hombre" (Arendt 2009, 81).

Un contrapunto necesario a esta posición y a esta sobrevaloración de la bondad la encontramos en un destacado republicano como Maquiavelo, el cual, refiriéndose al espacio público y apelando al proceder que cada momento necesita - "quien renuncia a lo que se hace en aras de lo que se debería hacer, aprende más su ruina que su conservación" (2006, XV, 110)-considera que la condición de ser bueno no es eximente para un porvenir catastrófico: "De ahí que un príncipe que se quiera mantener necesita aprender a no ser bueno, y a hacer uso de ello o no dependiendo de la necesidad" (Maquiavelo 2006, $\mathrm{XV}, 110)$.

Al contrario que en la civilización greco-romana, donde el espacio público y la actividad política era la vía habitual para una inmortalidad terrenal, la actividad pública y política con el cristianismo "se hundió al bajo nivel de una actividad sujeta a la necesidad, destinada a remediar las consecuencias de la pecaminosidad humana, por un lado, y a complacer los deseos e intereses de la vida terrena, por el otro" (Arendt, 2009, 339). Con la cosmovisión cristiana, por tanto, "la aspiración a la inmortalidad se equiparó a la vanagloria; la fama que el mundo concedía al hombre era ilusión, puesto que el mundo era mucho más perecedero que el hombre, y el esfuerzo para alcanzar la inmortalidad mundana carecía de significado, ya que la propia vida era inmortal" (Arendt, 2009, 339).

Maquiavelo también cuestionará este proceder cristiano que aparejaba la notoriedad con la vanagloria. Al igual que para la antigüedad clásica, la regla que marca el quehacer político es la consecución de la gloria, por lo que el uso de la crueldad o la maldad - como en el caso de Agatocles, tirano de Siracusa-, aunque consiga objetivos, impiden que estos sean gloriosos: "procedimientos así permiten adquirir poder, mas no gloria” (2006, VIII, 86).

De igual modo, si bien la maldad destruye el mundo común, Maquiavelo también considera que la apelación permanente a la supuesta bondad en el espacio público a través del dominio religioso sobre la esfera secular era motivo de preocupación. De esta suerte, estima Maquiavelo, al tiempo que las nuevas órdenes $^{7}$ "volvieron a instalar en la mente de los hombres la religión cristiana,

\footnotetext{
${ }^{7}$ Se refiere a las llamadas órdenes mendicantes fundadas en el siglo XIII por san Francisco (Orden
} 
que ya estaba olvidada, $[\ldots]$ pues sus miembros viven pobremente, y tienen mucho crédito entre el pueblo por sus confesiones y sermones" (1987, III 1, 294) también propiciaban la injusticia cuando, apelando a la bondad, enseñaron al pueblo a no resistirse al mal: "y así dan a entender que es malo hablar mal del mal que cometen los prelados, y que es bueno vivir bajo su obediencia, [...] y los prelados obran lo peor que pueden, pues no tienen miedo a un castigo que no ven y en el que no creen" (1987, III 1, 294).

El cambio de paradigma que produjo el cristianismo fue absoluto, formulando un nuevo concepto de comunidad y de miembro integrante de esta. En lo que respecta a la comunidad, como señala Arendt, "el carácter no público y no político de la comunidad cristiana quedó primeramente definido en la exigencia de que formara un corpus, un cuerpo, cuyos miembros estuvieran relacionados entre sí como hermanos de una misma familia" $(2009,63)$. Por otro lado, como elemento constituyente de esta colectividad, como persona, "fue precisamente la vida individual la que pasó a ocupar el puesto que tenía en otro tiempo la "vida" del cuerpo político" (Arendt 2009, 339). $Y$ en esta elaboración es importante la figura de Pablo de Tarso": "Es como si los primeros cristianos -al menos san Pablo, que después de todo era ciudadano romano- amoldaran conscientemente su concepto de inmortalidad según el modelo romano, sustituyendo la vida individual por la vida política del cuerpo político." (Arendt 2009, 339).

Es evidente que la Reforma protestante del siglo XVI se identifica con san Pablo, y persigue la vuelta al cristianismo originario; considerando que la Iglesia católica había perdido su nivel de exigencia primitivo, una vez que con Constantino se había convertido en la religión oficial del Estado y había erigido una estructura jerarquizada implacable, donde también se había abandonado la anterior perspectiva escatológica, reafirmada con el hecho de que "la experiencia demostró que incluso la caída del Imperio Romano no llevaba consigo el fin del mundo" (Arendt 2009, 79). Sin embargo, tras el declive del Imperio Romano, la Iglesia católica "ofreció a los hombres un sustituto a la ciudadanía que anteriormente había sido la prerrogativa del gobierno municipal" (Arendt 2009, 45-46), siendo este el modelo vigente en toda la Edad Media y cuya esencia era indudablemente comunitarista. Es precisamente en oposición a este sistema donde se fragua el retorno al mensaje evangélico originario, que está en el germen del cristianismo reformado e individualista y que, a su vez, es la raíz de la ética protestante que abre paso al liberalismo y su teoría política.

de Hermanos Menores) y santo Domingo (Orden de Predicadores).

8 "Pero gracias a Dios, que, aunque erais esclavos del pecado, $[\ldots]$ mas ahora, que habéis sido libertados del pecado y hechos siervos de Dios, tenéis por vuestro fruto la santificación, y como fin, la vida eterna. Porque la paga del pecado es muerte, mas la dádiva de Dios es vida eterna en Cristo Jesús Señor nuestro." (Carta a los Romanos, 5, 17-23).

Araucaria. Revista Iberoamericana de Filosofia, Política, Humanidades y Relaciones Internacionales, año $23, \mathrm{n}^{\circ} 48$. Tercer cuatrimestre de 2021. Pp. 9-31. ISSN 1575-6823 e-ISSN 2340-2199 https://dx.doi.org/10.12795/araucaria.2021.i48.01 


\section{De la disrupción a la continuidad}

A la hora de analizar la tematización que hace Hannah Arendt sobre la idea política del pensamiento medieval es preciso tener en cuenta la época en la que este análisis se realiza. Su mirada al medievo y al cristianismo nace de una interpretación de la historia del pensamiento víctima de la vulnerabilidad ideológica con que las filosofías sectoriales (como puede ser la filosofía política) acometen, con frecuencia, cuestiones relativas a la historia de la filosofía. La Edad Media resulta ser así una de las más agraviadas, condenando al ostracismo nada más y nada menos que catorce siglos de historia, aquellos en los que se forjó el logos de Occidente.

La historiografía actual tiene un acercamiento más exacto, menos acomplejado y más libre de la tiranía historiográfica romántica. Para ello, en primer lugar, realizaremos una breve reflexión sobre la pretendida disrupción entre Edad Media, Renacimiento y Modernidad que justifique el salto directo de Cicerón a Maquiavelo; y, en segundo lugar, bucearemos en otras fuentes medievales para rastrear el germen medieval-franciscano de las teorías republicanas modernas.

Es un lugar común, por lo tanto, posiblemente un mito falso ${ }^{9}$, que la configuración del llamado mundo moderno se conforme de forma rupturista a partir del Renacimiento y el Humanismo. Una parte del pensamiento del Renacimiento, primero, y, más tarde, del Romanticismo, ha transfigurado, incluso inventado, un periodo medieval entendido como contrapunto a un cierto tipo de pensamiento centrado en el humanismo y en una nueva iluminación desde la fuente de la razón. Se trata de una imagen que quiere subrayar el hecho de ruptura con la modernidad. Esa imagen, no obstante, se ha ido transformando.

La obra de Hans Blumenberg Die Legitimität der Neuzeit (1966) acentúa la figura de la secularización y del giro copernicano como espacios (mitológicos) de la Modernidad, mezclando temas, épocas, autores, y confundiendo ideas con ideologías. Estos ensayos, sin embargo, hace ya más de cuatro décadas que van casi desapareciendo de los estudios de los especialistas. De hecho, "la historiografía actual -afirman Ariane Boltanski y Aliocha Maldavsky- insiste al contrario sobre el hecho de que el Renacimiento no puede der considerado como una ruptura radical con el pasado que le precedió, sino que subraya sobre todo la continuidad entre una Edad Media, considerada actualmente con connotaciones positivas, y el Renacimiento" $(2002,11)$.

No podemos discutir ahora qué significa Modernidad, ni en qué consiste la Edad Moderna. Lo que sabemos es que, en parte, se construyó en base al olvido psicológico y el intento de superación mental de la Edad Media; pero también

\footnotetext{
9 Estas tesis se ven especialmente en el campo de historia de la ciencia, en autores como James Franklin (1982) o Edward Grant (1996).
}

Araucaria. Revista Iberoamericana de Filosofia, Política, Humanidades y Relaciones Internacionales, año $23, \mathrm{n}^{\circ} 48$. Tercer cuatrimestre de 2021. Pp. 9-31. ISSN 1575-6823 e-ISSN 2340-2199 https://dx.doi.org/10.12795/araucaria.2021.i48.01 
que, de facto, material, formal, espiritual e intelectualmente no se pudo dar sin esta. Esto nos lleva a considerar que es imposible pensar una discontinuidad tal que sea capaz de romper con el propio sentido común: "Rechazar la Edad Media es pasar por alto mil años de cultura, ignorar el aporte de la cultura árabe, del judaísmo, de los teólogos. Se trataría de un olvido de diez siglos, el paréntesis más grande en la historia del pensamiento" (Boulnois 2016, 329).

No parece lógico seguir anclados en el espíritu romántico de Michelet (1855) quien representó el Renacimiento como "la formación del mundo moderno", ni de Burckhardt, quien consagró el término en La civilización del Renacimiento en Italia (1860). Estos autores, apoyados en la obra del historiador holandés Huizinga Herfsttij der Middeleeuwen (1919) reinterpretaron el mito, para hablar de una época que rompió deliberadamente con la Edad Media, "una época de espíritu colectivo, religión y autoridad" 10 . Posiciones que eran proyecciones historiográficas en el pasado de una problemática de su tiempo (Tollebeck 2001). Este es el contexto historiográfico que Arendt contempla a la hora de acercarse en su análisis a la historia del pensamiento. Como consecuencia de ello, estas aproximaciones insisten en una dialéctica simplista entre escolástica, vista de forma uniforme, y humanismo renacentista, obviando, como señala Pasnau (2006), que no se puede afirmar la existencia de una uniformidad escolástica, al igual que no se produce la homogeneidad en ningún movimiento filosófico.

Somos conscientes de que al reflexionar el Renacimiento y la Modernidad hay que superar la tesis de continuidad-discontinuidad, para aterrizar en una posición natural donde conviven de forma especial la continuidad con elementos que podemos definir -superando la expresión "ruptura"- como renovación, diversidad, profundización o cambio de rumbo: "Es imposible que los individuos y los grupos rompan del todo con la cultura en que han sido formados. La paradoja esencial de toda reforma cultural es que los reformadores provienen de la cultura que desean cambiar" (Burke 2000, 9). Salvando las distancias, esto sucederá también con el hecho revolucionario respecto al Antiguo Régimen. Alexis de Tocqueville, en su estudio sobre la Revolución francesa ${ }^{11}$, rebate magistralmente esta tesis de la discontinuidad y valida la constatación de una continuidad, esto es, que los logros atribuidos a la Revolución se hubieran alcanzado igualmente sin ella, como resultado de las reformas ya emprendidas con anterioridad.

De igual forma, no se puede entender el periodo del Renacimiento sin tener en cuenta que los siglos XII y XIII son las bases de la modernidad y del periodo conocido como Renacimiento en la medida en que se ponen las bases

${ }^{10}$ El último y acabado ejemplo de este galimatías intelectual de aire neorromántico lo tenemos en Rafael Herrera (2020).

${ }^{11}$ Antonio Hermosa Andújar en la introducción a su edición de Tocqueville, El Antiguo Régimen y la Revolución, lo describe con claridad: "Tocqueville, tras documentadísimas investigaciones y un muy profundo estudio sobre la sociedad del antiguo régimen llegará, como dijimos, a conclusiones opuestas, remarcando, no sin sorpresa, la continuidad de la sociedad francesa más allá del pretendido abismo de la Revolución" (Tocqueville 2004, 11-12).

Araucaria. Revista Iberoamericana de Filosofía, Política, Humanidades y Relaciones Internacionales, año $23, \mathrm{n}^{\mathrm{o}} 48$. Tercer cuatrimestre de 2021. Pp. 9-31. ISSN 1575-6823 e-ISSN 2340-2199 https://dx.doi.org/10.12795/araucaria.2021.i48.01 
de una reinterpretación de la relación entre "natural" y "sobrenatural" a partir de la profundización y la renovación de los textos de la filosofía clásica. La recuperación de los clásicos y el profundo humanismo se forjan cuando el ser humano se cuestiona a sí mismo desde sus fuentes clásicas y reveladas.

El Renacimiento no alcanzó una verdadera separación de la ciencia y la teología, vertiendo las disputas en los modos de pensar y tomando como un elemento singular las fuentes clásicas. Aparecen así diversos renacimientos o concepciones renacentistas. Unos, unidos a la Reforma-el caso del protestantismo, especialmente Calvino-. Otros subrayan el renacimiento de las artes y las letras de la antigüedad, a partir de una generación de jóvenes latinistas italianos del siglo XV que estaban fascinados por las letras clásicas (latín y griego). Y otros, teólogos, ven en el humanismo renacentista la posibilidad de realizar una pedagogía teológica desde las nuevas formas de un método que supere el exceso de escolasticismo visualizado en el verbosismo.

Le Goff ha insistido en la permanencia de los rasgos medievales en el origen de la Modernidad (2014) y, excepto aproximaciones extemporáneas, se comprende una natural continuidad en la concepción renacentista que va desde los renacimientos medievales hasta el del siglo XVI (Lázaro, Bordoy y Llamas 2020). Por su parte, Jean Delumeau (1967) se preguntaba, ya en la década de los sesenta del siglo pasado, por el término "Renacimiento", mostrando la continuidad temporal y cultural con el periodo medieval, solo desde el cual se pudo realizar un salto, en parte, disruptor.

La ruptura siempre presenta caduco todo aquello que le precede, ocultando que de lo que se trata es de una eclosión que nace de la reconfiguración a partir de una nueva exégesis cultural de la propia tradición, desde el espíritu de la continuidad. Así lo señalan Dominique Boutet y Joëlle Ducos (2015), para quienes prevalece, al menos en la literatura, el espíritu de continuidad y no de ruptura, mostrando que la sensibilidad al descubrimiento es un movimiento fundamental que produce eflorescencia tan pronto como surge nuestra literatura en lenguaje vulgar, donde se mantienen relaciones complejas con la ficción que, no siendo relaciones de oposición, exigen ser descritas y sacadas a la luz.

Cuando Juan Andrea di Bussi (1496) utilizó la denominación de media aetatis de forma ideológica no tuvo un día feliz, pero él no seguía criterios historiográficos. Lo que es inadmisible es seguir perseverando en el espíritu oscurantista de pensar que esta época es un enorme hiato en la humanidad. Es pues una designación arbitraria que solo se puede aplicar al mundo europeo y de cultura latino-cristiana. Pero ¿cómo es pertinente establecer esta diferenciación temporal en aquellas culturas semíticas dominadas por el judaísmo y el islamismo? Solo tiene una utilidad metodológica, y esta es limitada, no solo porque se ve desde la perspectiva europea, sino porque encerrar este período como etapa intermedia entre dos épocas más extensas es 
ignorar la importancia que este período tiene en la influencia del pensamiento filosófico posterior. No se puede entender el pensamiento occidental ni la etapa moderna en su profundidad sin comprender las aportaciones intelectuales de la filosofía medieval: "si la Edad Media y los Tiempos Modernos son correlativos, es porque el ideal medieval ya era, en sus empresas intelectuales (es decir, reconozcámoslo, para una pequeña élite urbana) moderno" (Olivier Boulnois, 2016, 342).

Más que nunca cobran sentido las palabras de Boulnois (2016, 347):

Estudiar la Edad Media no consiste, pues, en dedicarse simplemente a consideraciones inactuales, es darse los medios para superar la crisis de los conceptos fundamentales de la modernidad, la crisis de la misma filosofía contemporánea.

Comenzamos preguntándonos: “¿Qué significa pensar?” Ahora podemos hacer esta otra pregunta que quizá sea sinónima: “QQué libera el pensamiento?” Ahora podemos responder: la Edad Media. La filosofía medieval nos parece hoy más que nunca esencial, porque nos libera de la tiranía del presente.

No es baladí tener una idea u otra del Renacimiento y de su conexión con el pensamiento medieval. La posición de Eugenio Garin de un Renacimiento contrapuesto a los tiempos medievales ya no se puede sostener, sin más, casi ochenta años después (Garin 1941). Pero es la posición que alimentó el nacimiento del movimiento republicano moderno y que ha tenido su reflejo en la idea de un Renacimiento cívico y homogéneo (Hankins 2000) en el último tercio del siglo XX, que perdura en los seguidores de Hannah Arendt. En sus trabajos alrededor de la década de los cuarenta del siglo pasado, Garin entrelazó el pasado y el presente estableciendo una relación entre la situación histórica concreta y las propuestas que estaba realizando a nivel científico al objeto de proponer un humanismo civil. A lo que debemos añadir, en el ambiente de posguerra, tanto la influencia mediadora de Antonio Gramsci como su militancia en el partido comunista italiano. Así se entiende que la idea de revitalizar el papel de la retórica en el humanismo civil para prevenir los recursos del fascismo y señalar la continuidad de la historia cultural italiana (Girard 2012) tuviera en Garin un valor sectorial y temporal tan específico.

Y ello no responde a la realidad. De hecho, si nos atenemos al estudio historiográfico entre metafísicos y retóricos, entre humanistas y filósofos, en la propia Florencia de finales del siglo XV, no se aprecia una distinción clara entre ellos. Como ha señalado Amos Hedelheit, desarrollando la visión historiográfica de Garin, no solo no es válida "la separación entre humanistas y filósofos", sino tampoco "la distinción entre los filósofos humanistas como Marsilio Ficino y Giovanni Pico della Mirandola, un teólogo escolástico profesional como Giovanni Caroli, y un predicador como Girolamo Savonarola" (2006, 272). 
Los estudios de Garin y su interpretación del Renacimiento italiano en clave "civil", responde a razones ideológicas que son de interés en cuanto ofrecen paradigmas de explicación y proyección en el tiempo presente -en el tiempo en que se escriben (Terza 1981)-, pero limitan la interpretación histórica, haciendo de la historiografía una metodología que sirve de coartada para afirmaciones ajenas a la interpretación histórica en su contexto, hasta el punto de alienarla de contenido y convertirla en un mero instrumento al servicio de las urgencias y propuestas de pensamiento propias del momento en el que son formuladas.

Es curioso que aquellos que vieron en el humanismo cívico y el republicanismo una alternativa al marxismo y al liberalismo anglosajón, cayeran en las garras de una historiografía sesgada que les impedía aprovechar un rico caudal de bases y fundamentos de aquello que querían promover; un olvido provocado por la lectura que de su obra realizara Hans Baron (1967), quien lo llevó al ámbito anglosajón. En todo caso, lo que podemos constatar es que, aunque entendamos el contexto de pensamiento de las lecturas que Arendt y parte del pensamiento anglosajón realizaron de la historia del pensamiento y de una visión particular del Renacimiento, es necesario señalar que esta lectura implica una mala interpretación del universo medieval y de su continuidad, así como de sus posibilidades políticas. Igualmente hay que señalar que es errónea esta exégesis del republicanismo liberal y de la importancia de la vida activa -tal como Arendt lo interpreta en tanto que antídoto del totalitarismo (Hankins 2003, 582) - como caudal de pensamiento, pues como veremos esta es la formulación donde se puede ver cómo la forma vitae alimentará la forma mentis, y especialmente en el pensamiento franciscano. El humanismo renacentista ataca las formas anquilosadas de la lógica, el verbosismo, atendiendo a las formas de persuasión y la retórica, pero mientras unos reparan en la fuerza de la voz, los aspectos sintácticos y comunicativos (del nombre, una lectura retórica del nominalismo) para abordar la cuestión civil, otros atienden a los aspectos semánticos inherentes a la acción política (franciscanismo escotista).

\section{Los gérmenes franciscanos medievales del republicanismo}

Al inicio del trabajo, al analizar el republicanismo cívico de Arendt, señalábamos la lectura que la pensadora hace del cristianismo y Maquiavelo. Tres temas nos llaman la atención: (1) La dialéctica entre poder civil y eclesiástico. (2) La sobrevaloración del bien. (3) El sometimiento del pueblo contra el mal. Todo ello criticando especialmente las órdenes mendicantes todas confundidas, como si dominicos y franciscanos fueran iguales. Sin embargo, la Edad Media es un periodo muy rico en matices y lecturas. No será igual el pensamiento de Tomás de Aquino, fundamentado en el realismo filosófico 
conforme a una metafísica del esse, una ontología in re y una teorización desde el desarrollo de la causalidad en el orden natural a partir del sobrenatural basado en la analogía, que el del franciscanismo, especialmente el escotista, sustentado en una metafísica del ens, una ontología quidditativa desde la realidad de la haeccitas (concreción ontológica como esteidad) y una teorización desde la omnipotente voluntad (absoluta y ordenada) asentada en la univocidad. Más diverso será aún el nominalismo de Ockham en base a una teoría de la segunda significación y la separación del orden natural y el sobrenatural.

Pero no vamos a abundar en esta cuestión, y centrándonos en el tema que nos concierne, vamos a presentar en líneas muy generales cuatro muestras de la aportación franciscana al republicanismo político: el ejemplo práctico de Francesc Eiximinis y sus bases teóricas; Buenaventura, Duns Escoto (Guillermo de Ockham realiza una lectura específica dentro de la tradición franciscana que de hecho, supondrá, una mirada específica que revertirá en una interpretación de un voluntarista a-racional y un nominalismo que es espurio a Escoto), y ya en el siglo XVI a Alfonso de Castro. Las cuatro posiciones representan una versión del republicanismo diferente a la maquiavélica, a la vez que responden a una óptica más amplia y con referencias ontológicas más fuertes.

Francesc Eiximenis (1330-1409) presenta un ejemplo de teorización del republicanismo franciscano medieval en su obra Regiment de la cosa pública (1383). Partiendo de las fuentes aristotélicas (realidad política), estoicas (teoría de la virtud) y del derecho romano (teoría jurídica), afirma que la ciudad es una realidad presente en el estado de naturaleza del hombre cuya organización puede ser pensada por la razón. En esta vida del hombre en sociedad, tal como muestra el derecho romano, "la ley debe ser la norma rectora que permita al hombre ir recto en la verdad" (Eiximenis 2012, 95-96). Ella es garante del pacto político (Giesey 1968, 277) y está sustentada en la virtud cívica, sobre la que orbita la norma que evita que el abuso y la corrupción se ejerza entre los miembros de la comunidad, sea cual fuere su condición, especialmente en aquellos que son los pilares de la comunidad -magistrados y cargos públicos-. Por tanto, mientras que el nudo gordiano ético de la comunidad política es la virtud cívica, será el pacto la esencia de la política, la fuente de donde emana el poder político. Y es en este ámbito donde la libertad es entendida como la responsabilidad en la esfera pública. En definitiva, esta obra es una propuesta en la que, introduciendo el pacticismo que la monarquía representa (Cervera 1989, 138-139), se expone una teoría del poder ancestro del pensamiento democrático republicano. Salvador Giner, estudioso del republicanismo, se lamenta de la injusticia que supone la ausencia de Eiximenis en la lista de los promotores de esta corriente, reivindicado su memoria junto a Maquiavelo, los pensadores ingleses o Arendt durante el siglo XX $(2010,26)$. 
Así pues, el pensamiento político de Eiximenis se circunscribe y nos ofrece una versión del pensamiento franciscano, que insiste en la necesidad de un fundamento antropológico (y ontológico) del concepto de ciudadanía y de virtud cívica, donde se esencializa el republicanismo como res publica y no como forma de gobierno, representando lo segundo una condición secundaria.

El franciscanismo nace en el seno de la civitas. A diferencia del mundo rural feudal (experiencia monástica), la vida conventual es urbana. Los franciscanos son conscientes de que la civitas es un elemento intrínseco a la constitución histórica de la existencia humana. Como en Agustín, los franciscanos tienen la conciencia de que, como civitas, la comunidad política tiene su propio Derecho y que la civitas de la comunidad humana histórica es producto de los hombres. Pero ello no emana de un trasunto de la ley divina sobre la humana, sino que tiene su base, como dirá el Agustín original, en la búsqueda ciceroniana de una legitimación del Estado que descansa en la defensa de la justicia como su razón de ser. Como señala Sergio Cotta analizando De libero arbitrio: "S. Agustín acaba de subrayar con fuerza, en De libero arbitrio, que la ley temporal no castiga, ni puede castigar, el pecado moral, el amor a los bienes finitos, sino sólo - permítaseme la expresión- el pecado jurídico, la violación de los derechos de los demás" (Cotta, 1961, 168). Esta referencia a Agustín es fundamental, ya que el de Hipona parte del pueblo (populus), que es donde se constituye el "contrato social" entre individuos como la fuente jurídica en base a la justicia aceptada por todos en aras de objetivos comunes (Muñiz 2014-2015, 190). El ser humano se siente miembro de la civitas en la medida en que interioriza y se siente partícipe de la ley que la constituye. Así, en los franciscanos, guardianes, provinciales y generales tienen una responsabilidad limitada en el tiempo y son elegidos por los miembros de la fraternidad: la auténtica communitas.

También Buenaventura es consciente de la naturaleza cívica de la vida pública y de la importancia que tiene fomentar las virtudes del pensamiento ciceroniano $(1891,476)$, donde se relacionan el derecho romano y la obligación natural (Feenstra, 1979). De este modo, la ética y la política naturales (el derecho natural) conocen obligaciones basadas en el vínculo de la igualdad (vinculus equitatis) de claras lecturas sociales, ya que estas nacen de la naturaleza humana y son leídas por su racionalidad. Así, para Buenaventura, sobre la base jurídica del derecho romano (y la distinción entre obligación natural y civil) se establece el elemento básico de la convivencia humana, en tanto que existe una predisposición natural reconocida por la razón para la actuación de la razón práctica desde la afección: la "fraternidad universal". Esta abre el camino a la comunidad, marcando la experiencia práctica de la implantación de la orden en los territorios urbanos: la fraternitas es el lugar religioso propio de la nueva civitas (Lambertini 1999). 
Con arreglo a esta idea de comunidad y ciudadanía, la búsqueda permanente de la perfección en nada casa con la apreciación de Arendt sobre la injusticia sobrevenida en la apelación a la bondad, enseñando al pueblo a no resistirse al mal. Nada más lejos de la realidad. La acción de la fraternitas sobre la civitas trajo consigo frutos civiles de contenido republicano. Desde la teología práctica promoverá acciones positivas comunitarias tendentes a la lucha contra el mal, de modo que, fomentando la vida austera y pobre para la perfección evangélica, se alzará contra la pobreza sociológica (como muestra la creación de los Montes de Piedad). Todos los miembros de la comunidad pertenecen a la civitas, puesto que en el cristianismo no existe diferenciación entre pueblo y plebe, como en Roma. Todos sus miembros tienen la plenitud de la ciudadanía -el populus Dei- (Muñiz 2014-2015, 79). El fundamento abierto a una dignidad del pueblo, basado en la concepción ontológica de la persona abierta a la profunda fraternidad, fue sin duda el gran olvido del republicanismo italiano, lo que supone, en cierto sentido, más una vuelta atrás en el tiempo que un avance en la línea cívica.

Asimismo, será Duns Escoto quien, desde otra clave ontológica, fundamentará la fraternidad de la civitas en la vocación universal y originaria de la dignidad personal. El Sutil es consciente del carácter histórico (pro statu isto) de la situación humana (contingencia entitativa) en su realidad lapsa. El hombre (homo viator) camina con otras personas, es "un animal social" (al menos conyugal y doméstico), pero no es un "animal político". Su naturaleza personal abierta a la relación le hace ser social, pero su naturaleza no le lleva a la organización política, puesto que el orden político tiene carácter histórico. Por lo tanto, se trata de una organización voluntaria de personas, lo que cuestiona su reflejo natural. Como asociación humana libre, sus miembros escogen una estrategia de ordenación en pro del bien común de los hombres, construyendo su escala de valores. Además, esta axiología no tiene que concordar con el bien divino, por lo que dichas prácticas políticas no se fundamentan en virtudes morales trascendentes, sino en virtudes que podemos llamar "políticas". Esta naturaleza política es la que fundamenta el bien común, y sobre la que se establece la autoridad.

El bien compartido tiene carácter político en cuanto que busca la "convivencia pacífica" sustentada en la dignidad humana. En este orden existe una igualdad intrínseca (no nominal, sino ontológica-haeccitas-) de los seres humanos cuya definición entitativa es la persona abierta a la relación. La persona es lo que define a cada uno, lo hace ser quien es, es la última respuesta a la vocación divina. Y estas personas no conocen una potestad de orden, ni esta define la potestad de jurisdicción: "la distinción jerárquica establecida en el orden es tan solo razón suficiente de la distinción entre los diversos órdenes de los entes" (Todisco 2004, 309). Es aquí donde se fundamenta la vida fraterna 
de los hombres libres que deciden organizarse, porque la sociedad es un "hecho cultural", en la que la convivencia pacífica aparece como un principio positivo. La sociedad civil (civitas) se fundamenta en el consenso nacido en el seno de los individuos que conforman voluntariamente una sociedad (Duns Escoto 1894, 266a [Oxoniense, IV, d. 15, q. 2, n. 7]). Sus vínculos son de condición políticomoral, de donde emanan comportamientos como el fiarse o la fe, la veracidad, la fidelidad, la amistad y la caridad. Se trata de las categorías vinculantes de la libertad. No se trata de un organizarse para luchar contra el caos nacido del pesimismo antropológico (Reforma, Hobbes...), con referencias obsesivas por lo contractual, maniqueo y apocalíptico, sino de una actividad de cooperación en el auxilio divino de la gracia en un hombre que es de naturaleza contingente. La perfección vendrá alimentada por la referencia a los valores divinos. Como toda actividad humana libre, la ordenación en la sociedad civil tiene elementos que pueden conducirla de modo que refuerce y oriente su capacidad de decisión en la forma de llevar a cabo su bien común, su convivencia pacífica, y esto lo tenemos en la interpretación de la Revelación.

El hombre, en tanto entidad libre y en su apertura comunitaria, no está al albur de los vaivenes de su condición histórica (quizás esto es lo que diferencia radicalmente el republicanismo franciscano del de Maquiavelo y del negativismo y pesimismo hobbesiano). Está referenciado a una base normativa cuyo fundamento es el amor, reflejo del amor de Dios y a Dios, que constituye el principio axiológico moral: un principio que nace de sí mismo, del propio acto de amor de sí mismo de la persona trinitaria en su acción de relación. Por tanto, la sociedad civil está constituida por personas libres que viven en sociedad y en orden a ello pueden hacerlo de diversas formas y maneras, todas legítimas, pero no todas igual de perfectas.

En consecuencia, el republicanismo franciscano se nos presenta como un espacio de referencialidad ontológica prepolítica y de decisión libre positiva donde las voluntades de las personas libres se ejercitan en la búsqueda de la fraternitas bonaventuriana y la perfección nacida del amor de Dios escotista: la comunidad de amor intratrinitaria.

En el siglo XVI, Alfonso de Castro, franciscano, teólogo, humanista y jurisconsulto (Lázaro, 2020), proyecta el republicanismo de origen franciscano como alternativa a otros proyectos cívicos del Renacimiento, consciente de la potencialidad de este republicanismo y compartiendo con otros escolásticos la naturaleza social del poder como es el caso de Castillo de Bobadilla, por citar un ejemplo (Coujou, 2018, 333). Para ello realiza una interpretación del bien común aristotélico desde el presupuesto de la organización civil franciscana, donde la libertad intrínseca del hombre, que toma las decisiones desde la facultad volitiva ante la presentación de la opción racional, constituye su fundamento antropológico esencial: "las leyes promulgadas por los príncipes o 
por los magistrados de una república tienen valor en cuanto se conciben como expresión de la voluntad del pueblo" (Castro 1931, 35).

Alfonso de Castro es consciente de la esencia humana de la sociedad fundada en el bien común. Sin despreciar el criterio de utilidad, equilibra el interés individual con el interés común. Y ello con la ventaja de evitar el juego de intereses formulado desde la lógica del poder. De ahí que, tras utilizar el símil del cuerpo humano como cuerpo social, afirma que "cualquier particular, aunque se llame rey, por lo mismo que no puede considerarse más que uno de tantos miembros de la sociedad, debe atender antes al bien social que al bien privado y mirar antes por el bien de la república que por la utilidad personal" (Castro 1931, 26). Alfonso de Castro es consciente de que la naturaleza humana radica en la expresión de su voluntad como el receptáculo de su libertad y criterio de humanidad y ciudadanía. El ser humano comparte la conidición común con otros seres, siendo la libertad el reflejo de la conveniencia compartida que le es propia y anterior a todo consensualismo. El pacto no es solo un criterio de voluntad sociológica, sino que tiene una profunda radicalidad antropológica, puesto que la voluntad es una realidad ontológica humana que se expresa en su actividad y es así la fuente última de las leyes positivas. Por eso la "ley es la voluntad recta del que dirige a un pueblo en nombre de este, promulgada de palabra o por escrito, y con intención de que los súbditos queden obligados a la obediencia" (Castro 1931, 12).

La ley humana no es natural, pero expresará mejor la universalidad común del bien compartido si es capaz de asemejarse a la ley natural. Por lo tanto, no se trata aquí de entender un moderno convencionalismo, sino de fundamentar la ley en un presupuesto antropológico fundamental que nace del ser común del hombre como fuente de su bien común. Los hombres unen su libertad para realizar una ley, que para que sea tal ha de ser justa, y, por lo tanto, no puede obviar el bien común a todos los hombres, como recordaran los clásicos, citando en este momento del discurso a san Isidoro. Por eso no cabe en la ley la excepción o el "privilegio", escaparate y expresión del ejercicio tiránico del poder: "La ley que se da para utilidad común de todos los ciudadanos es ley justa" (Castro 1931, 25). Con esta formulación, Alfonso de Castro recupera el fundamento franciscano de la naturaleza de la república, que está en la base de la libertad íntima del hombre y de su radical igualdad: la fraternidad. Ahí radica el sustento último del poder cívico: "Aún después de caída la naturaleza humana, nadie es rey o señor por derecho natural, sino que estos son señores o reyes, cuando lo son justamente, por consentimiento del pueblo" (Castro 1931, 33). 


\section{Conclusión}

La experiencia radical de la fraternitas de hombres radicalmente libres fundamenta los dos elementos imprescindibles del republicanismo que señalara Skiner como comunidad autogobernada: el estar en contacto con los otros y la existencia de la esfera pública de semejantes. El salto "cuántico" de parte de la historiografía, eliminando a la Edad Media de cualquier ecuación del crecimiento del pensamiento occidental, lo padeció Hannah Arendt y los re-editores del republicanismo cívico, hurtando con ello a este pensamiento político de un sistema referencial fundamental para realizar un republicanismo universal. No solo a nivel histórico se desaprovecha el caudal aristotélico presente en el Humanismo por vía del medioevo, sino que, además, se malinterpreta, por simplificación y reducción, la complejidad de los matices medievales y, lo que es aún más empobrecedor, se pierde una lectura como la franciscana, que dota al republicanismo de una profundidad semántica y de una estructura sintáctica que, por otra parte, ha sido clave en la constitución pragmática del lenguaje republicano y de sus posteriores proyecciones. No se puede entender a Maquiavelo, ni al pensamiento político de Hobbes o Rousseau, y mucho menos a Montesquieu, sin atender a la conceptualización de la escolástica medieval, renacentista y barroca, que constituyeron un verdadero curriculum oculto de sus teorizaciones.

Si en el republicanismo actual se destaca al ciudadano, que es concebido y se percibe a sí mismo como vinculado a su ciudad, a su patria o a su comunidad, esto es, como un sujeto político comprometido que considera que la garantía de su libertad solo es posible en una comunidad de semejantes que se autogobierna, todo ello no hubiera calado en nuestras conciencias sin el aldabonazo y la resonancia que supuso en la comunidad cristina la experiencia franciscana. A través de ella, fundamentada en la dignidad humana, los hombres libres deciden organizarse como comunidad a través de vínculos de naturaleza político-moral para conformar una sociedad donde la convivencia pacífica y vida fraterna nace del consenso que emana de los individuos que conforman voluntariamente la nueva civitas. Abiertos a la comunidad humana y compartiendo, además, su vivencia con el resto de las personas, la nueva comunidad "política" no se define por la sangre ni por los genes, no se inserta en el mundo rural feudal como la experiencia monástica, sino que la experiencia conventual tiene su lugar en la urbe y se concibe como civitas, con su propio Derecho y como un producto histórico de hombres libres. Además, esta aspiración no surge como una copia de la ley divina, sino que tiene su razón de ser en el impulso humano por la búsqueda y promoción de la justicia, para cuya salvaguarda se precisa de una comunidad política de raigambre ciceroniana y agustiniana que asuma colectivamente este anhelo, promulgando normas que impulsen a erradicar 
la servidumbre, garantizando la dignidad humana y el respeto a la esfera de acción libre que corresponde legítimamente a los conciudadanos.

El pesimismo antropológico maquiaveliano o la instauración de una "teología de la pesadilla" hobbesiana -sumiendo la dignidad humana en una situación presocial en la que cada uno es un competidor para su semejante y donde sólo una potencia todopoderosa, la del Estado, puede garantizarle el derecho a la vida- no permitían percibir la aportación y el camino franciscano hacia una secularización de la política. En ella, los hombres, más allá de cualquier contractualismo, unen su libertad para realizar la ley, que, para que sea tal, ha de ser justa y, por lo tanto, no puede obviar el bien común para toda la comunidad.

Ya Montesquieu, republicano confeso, consideraba que la virtud política exigía renuncia de uno mismo, por lo que la ley común debe ser para utilidad común de todos los ciudadanos, no para beneficio de un particular, porque eso es excepción o "privilegio", antesala del ejercicio tiránico del poder. Porque, efectivamente, puede existir una republica tiránica que imponga una tesis totalitaria más allá del Estado de derecho, igual que una forma monárquica puede perfectamente estar sustentada por una base constitucional y representar, en su neutralidad, la garantía del pacto. Por eso, el republicanismo, más allá de una forma de gobierno es un orden político que necesita de la responsabilidad de los ciudadanos. Solo teniendo presente la libertad íntima del hombre y su radical igualdad (fundamentos franciscanos de la naturaleza fraterna de la república, como recordara Alfonso de Castro) podremos practicar una auténtica virtud cívica, capaz de hacernos mantener una actitud vigilante ante la corrupción y la transgresión de las leyes y normas que nos hemos dado para vivir juntos y así mantener el espacio compartido del que nos hemos dotado.

\section{Referencias bibiográficas:}

Antonini, Bruno. 2012. "Penser le politique et le droit. Sur un retour du républicanisme". Cahiers Jaurès 205-206 (3): 105-135.

Arendt, Hannah. (1958) 2009. La condición humana. Traducción de Ramón Gil Novales. Buenos Aires: Paidós.

Baron, Hans. 1967. "Review: Italian Humanism: Philosophy and Civic Life in the Renaissance. By Eugenio Garin. Translated by Peter Munz. (New York: Harper and Row, 1965, XXIV, 227)". The American Historical Review 72 (2): 631-633.

Blumenberg, Hans. 1966. Die Legitimität der Neuzeit. Frankfurt am Main: Suhrkamp. 
Boltanski, Ariane y Aliocha Maldavsky. 2002. La Renaissance des années 1470 aux années 1560 (envisagée dans toutes ses dimensions). Paris: Éditions Bréal.

Boulnois, Olivier. 2016. “Qué hay de nuevo? La Edad Media”. Universitas Philosophica 33: 321-350.

Boutet, Dominique y Joëlle Ducos. 2015. Savoirs et fiction au Moyen Âge et à la Renaissance. Paris: Presses Sorbonne Université.

Buenaventura. 1891. Collationes de septem donis Sipiritus Sancti. En Opera Omnia, Vol. V, editado por PP. Colegii a S. Bonaventura, 455-503. Florentiae: Ad Claras Aquas (Quaracchi).

Burckhardt, Jacob. 1860. Die Cultur der Renaissance in Italien: Titelzusatz:ein Versuch. Basel: Schweighauser.

Burke, Peter. 2000. El Renacimiento Europeo. Centros y periferias. Traducido por Magdalena Chocano Mena. Barcelona: Crítica.

Castro, Alfonso de. 1931. La fuerza de la ley penal. De potestate legis poenalis. Traducción de Laureano Sánchez Gallego. Murcia: Universidad de Murcia, Sucesores de Nogués [reimpresión facsímil: 2005. Pamplona: Analecta ediciones].

Cervera, Luis. 1989. Francisco de Eiximenis y su sociedad urbana ideal, Madrid: Swan.

Cotta, Sergio. 1961. "Droit et justice dans le De libero arbitrio de St. Augustin". Archiv Für Re-chts- Und Sozialphilosophie 47: 159-172.

Coujou, Jean-Paul. 2018. "Fondement et finalité de la société chez Castillo de Bobadilla". Cauriensia 13: 325-360.

Delumeau, Jean. 1967. La civilisation de la Renaissance. Paris: Arthaud.

Duns Escoto, Juan. 1894. Quaestiones in quartum librum sententiarum. En Opera omnia, vol. XVIII. Paris: Éd. Vivès.

Eiximenis, Francesc. 2012. Le Gouvernement de la République. Traducido por Patrick Gifreu, Perpignan: Éd. de la Merci.

Feenstra, Robert. 1979. Droit roman au Moyen Age (1100-1500). Bruxelles: Éd. de l'Université.

Franklin, James. 1982. “The Renaissance Myt”. Quadrant 26: 51-60.

Garin, Eugenio. 1941. Il rinascimento italiano. Milano: Istituto per gli studi di politica internazionale.

Giesey, Ralph A. 1968. If Not, Not. The Oath of the Aragonese and the Legendary Laws of Sobrarbe. Princeton: Princeton University Press.

Giner, Salvador. 2010. "Francesc Eiximenis i els orígens del republicanisme". L'Espill 34: 26-33.

Girard, Pierre. 2012. “' 'Savoir historique' et transition. Le parcours d'Eugenio Garin”. Laboratoire italien 12. Acceso 23 de septiembre de 2020. doi: https://doi.org/10.4000/laboratoireitalien.659. 
Grant, Edward. 1996. The Foundations of Modern Science in the Middle Ages: Their Religious, Institutional, and Intellectual Contexts. Cambridge: University Press, Cambridge.

Hankins, James. 2000. "Introduction". En Renaissance Civic Humanism: Reappraisals and Reflections, editado por James Hankins, 1-13. Cambridge: Cambridge University Press.

. 2003. Humanism and Platonism in the Italian Renaissance. I Humanism. Roma: Ed. di Storia e Letteratura.

Hedelheit, Amos. 2006. "Humanism and Theology in Renaissance Florence: four examples (Caroli, Savonarola, Ficino, and Pico)". Verbum Analecta Neolatina 7 (2): 271-290. doi: 10.1556/Verb.8.2006.2.1.

Herrera, Rafael. 2020. La primera filosofía moderna: el Renacimiento. Madrid: Tecnos.

Huizinga, Johan. 1919. Herfsttij der Middeleeuwen: studie over levens- en gedachtenvormen der veertiende en vijftiende eeuw in Frankrijk en de Nederlanden. Haarlem: H. D. Tjeenk Willink.

Lambertini, Roberto. 1999. "Lo studio e la recezione della Politica tra XIII e XIV secolo. Da Egidio Romano a Giovanni di Parigi, da Dante a Marsilio: fautori ed oppositori della teocrazia papale agli inizi del Trecento". En Il pensiero politico. Storia, idee, dottrine, editado por Carlo Dolcini, vol. 1, 1555-1563. Torino: Utet.

Lázaro, Manuel. 2020. "Alfonso de Castro, inter theologos iuriconsultissimus: De justa haereticorum punitione, libri tres. Una introducción”. Cauriensia 15: 483-504.

Lázaro, Manuel, Antoni Bordoy y Vicente Llamas. 2020. La presencia del pensamiento clásico en la filosofía medieval. Madrid: Sindéresis-UPSA.

Le Goff, Jacques. 2014. Faut-il vraiment découper l'histoire en tranches? Paris: Seuil.

Lovett, Frank 2018. "Republicanism". En The Stanford Encyclopedia of Philosophy. Acceso 21 de septiembre de 2020. https://plato.stanford.edu/ archives/sum2018/entries/republicanism/.

Maquiavelo, Nicolás. 1987. Discursos sobre la primera década de Tito Livio. Traducido por Ana Martínez Arancón. Madrid: Alianza Editorial. 2006. El príncipe, traducción y estudios preliminares por Antonio Hermosa Andújar. Buenos Aires: Prometeo libros.

Michelet, Jules. 1855. Histoire de France au seizième siècle. Renaissance. Paris: Chamerot.

Montesquieu. (1748) 1995. El espiritu de las leyes. Introducción de Enrique Tierno Galván y traducción de Mercedes Blázquez y Pedro de la Vega. Madrid: Tecnos. 
Muñiz, Julio César. 2014-2015. “5. Populus”. Antigüedad y cristianismo. 21-22: 65-80 [Monografías históricas sobre la Antigüedad Tardía: Civitas y cives en San Agustín. La construcción de la Iglesia como Estado: Fundamentos de orden constitucional].

Pasnau, Robert. 2006. "A Theory of Secondary Qualities". Philosophy and Phenomenological Research 73: 568-591.

Pettit, Philip. (1997) 1999. Republicanismo. Una teoría sobre la libertad y el gobierno Traducido por Antoni Domènech. Barcelona: Paidós.

Pocock, John Greville Agard. (1975) 2017. El momento maquiavélico. El pensamiento florentino y la tradición republicana atlántica. Estudio Preliminar y notas de Eloy García, y Trad. de Marta Vázquez-Pimental y Eloy García. Madrid: Tecnos.

Rousseau, Jean-Jacques. (1762) 1964. CEuvres complètes. Volume III (Du Contrat Social. Écrits politiques). Paris: Gallimard.

Skinner, Quentin. (1998) 2004. La libertad antes del liberalismo. Traducción de Fernando Escalante. México: Taurus-CIDE.

Spitz, Jean-Fabien. 1995. La liberté politique. París: P.U.F.

Terza, Dante della. 1981. "Eugenio Garin, critico della cultura italiana contemporanea". Belfagor 36 (4): 381-97.

Tocqueville, Alexis de. (1856) 2004. El Antiguo Régimen y la Revolución. Edición, introducción y traducción de Antonio Hermosa Andújar. Madrid: Istmo.

Todisco, Orlando. 2004. "Ética y economía”. En Manual de Filosofía franciscana, editado por José Antonio Merino y Francisco Martínez, 249327. Madrid: BAC.

Tollebeek, Jo. 2001. “'Renaissance' and 'fossilization': Michelet, Burckhardt, and Huizinga”. Renaissance Studies 15 (3): 354-366.

Viroli, Maurizio. 1999. Repubblicanesimo. Roma-Bari: Laterza. 
